\title{
Healthcare Spending Overshoots a Threat to Sustainability
}

by

\author{
William B.P. Robson
}

\begin{abstract}
- Government spending on health has tended to grow faster than Canada's economy, raising concerns about the fiscal sustainability of our healthcare system.

- Initial estimates of provincial and territorial government spending on healthcare and public health in the Canadian Institute for Health Information's annual National Health Expenditure (NHEX) report suggest sustainable growth rates, but these figures reflect only intentions. Past history tells us that the revised, actual figures are typically materially higher.

- These revisions reflect a tendency for governments to overshoot their budget targets generally and in health-related programs particularly. Ensuring that publicly funded healthcare is fiscally sustainable will require better spending discipline overall and changes to better align the activities of managers, providers and patients with our capacity to pay.
\end{abstract}

The Canadian Institute for Health Information's (CIHI) annual NHEX report is a unique compilation of the sources and applications of funds used to promote, maintain and restore Canadians' health. Unfortunately, one element in the NHEX reports that generates a high profile - the preliminary numbers for healthcare spending by provincial and territorial governments - has tended to be misleading. CIHI derives these preliminary numbers from government budgets and estimates: i.e., planned expenses. Later revisions based on actual expenses have typically shown higher numbers. Preliminary numbers in successive NHEX reports earlier this decade showed health-related

This report updates previous work on the NHEX reports, notably Robson 2018. I thank members of the C.D. Howe Institute's Health Policy Council, Tom Closson, Livio Di Matteo, Brent Mizzen, Rosalie Wyonch, and reviewers of those earlier papers on this subject, for useful discussions and comments. Responsibility for any errors and for the recommendations is mine. 
spending decelerating more than the later numbers. And the preliminary numbers in more recent reports have understated the reacceleration since mid-decade.

Over the NHEX reports' 20-year history, the later numbers on average have shown provincial and territorial health expenses growing 0.8 percent annually faster than the preliminary estimates. Overshoots that large across the country, year after year, affect judgments about whether publicly funded healthcare is fiscally sustainable. For example, the preliminary 2018 number for overall growth of healthcare expenses is 3.8 percent - in line with most estimates of potential GDP growth. But an upward revision typical of past performance would put the final 2018 figure at 4.6 percent - faster than potential GDP growth and prefiguring some combination of rising taxes, more borrowing and squeezes on other government programs.

Two key points emerge from this review.

One is a caution. Governments tend to project smaller increases in healthcare spending than those that actually occur. So any conclusions drawn from preliminary numbers are premature and likely misleading on questions such as whether we have "bent the curve" in healthcare spending.

The other is that governments that wish to sustain their current healthcare systems need to address chronic spending overshoots. Provincial and territorial governments presumably try to budget increases in health-related spending that are fiscally sustainable. They do, however, have trouble making their budget targets stick. Bringing actual expenses into better line with governments' fiscal capacity will require better budgetary discipline overall and reforms to better align what officials, managers, providers and patients do with what the taxpayer can sustain in the long term. Budgeting sustainable increases in healthcare is easier than achieving them.

\section{Why the NHEX Numbers Matter}

For several years in a row early in this decade, CIHI accompanied its NHEX reports with news releases emphasizing declining rates of growth in healthcare spending. ${ }^{1}$ These releases attracted attention among health policy experts because they bore directly on the question of sustainability. Many people warn that slower growth of the economy and the tax base will depress the funding base for government-provided healthcare, while aging, new treatments, rising expectations and powerful provider groups push costs up. ${ }^{2}$ For the first decade in this century, the NHEX reports - like other measures - had shown health-related spending rising at rates well beyond the economy's ability to grow. Then the preliminary numbers for the years 2011 through 2015 appeared to show that spending had decelerated to rates that posed no threat to sustainability.

Less happily, the preliminary numbers in the most recent three years show a reacceleration. And there is a deeper problem. Each year's NHEX report draws its preliminary numbers (the light blue bars in Figure 1) for the then-current year from government budgets and other plans. Each report also contains revised numbers

1 The 2015 NHEX report emphasized modest recent increases (CIHI 2015), and each of its predecessors in 2012, 2013 and 2014 (CIHI 2012, 2013, 2014) highlighted decelerations from prior growth rates that observers often characterized as fiscally unsustainable.

2 See Busby, Robson, and Jacobs (2014) for projections of how healthcare and other demographically sensitive programs and taxes will squeeze provincial budgets in the coming decades. 


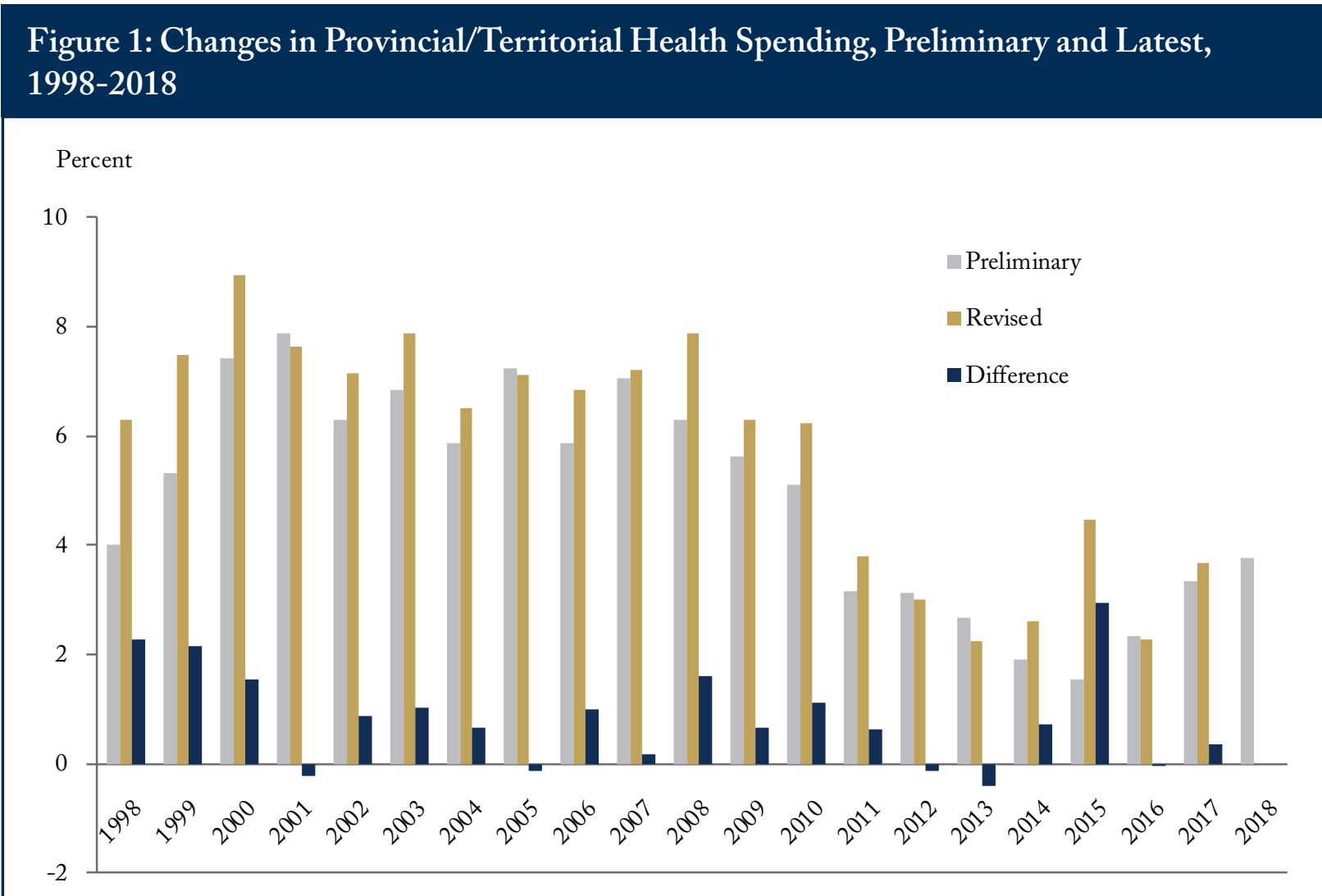

Source: Author's calculations from CIHI NHEX reports.

for previous years, based on actual expenses. ${ }^{3}$ The revised numbers (the gold bars in Figure 1) in later reports confirmed that health-related expenses have been growing more slowly since 2011. But the preliminary numbers - which people naturally focus on - exaggerated the improvement. On average, the revised numbers have typically shown growth rates 0.8 percent faster than the preliminary ones over the NHEX's history. More seriously, the difference in growth rates has been 1.0 percent in the most recent four years for which revised numbers are available (the dark blue bars in Figure 1 show the differences between the preliminary and the revised numbers). A key new data source - Statistics Canada's compilation of government spending by function - confirms the

3 Each NHEX report since the first in 1998 provided historical figures since 1975 and estimates for both the year of the report and the previous year. That lets us compare successive reports to see how CIHI revised its preliminary estimates as actual figures became available. For example, we can compare the increases shown for 1998 in the 1998 NHEX report with the increases shown for 1998 in the 2018 report, the increases shown for 1999 in the 1999 report with those for 1999 in the 2018 report and so on. In the 2018 report, 2016 is the most recent year based on final numbers, while the numbers for 2017 are revised, but not yet final. So the 2018 report provides 19 years (1998 to 2016) of final numbers that we can compare with the preliminary estimates for those years, as well as revised figures for 2017 that we can compare with the preliminary estimates for that year. 


\section{Figure 2: Changes in Provincial/Territorial Health Spending by Jurisdiction, 2014-17,} Averages

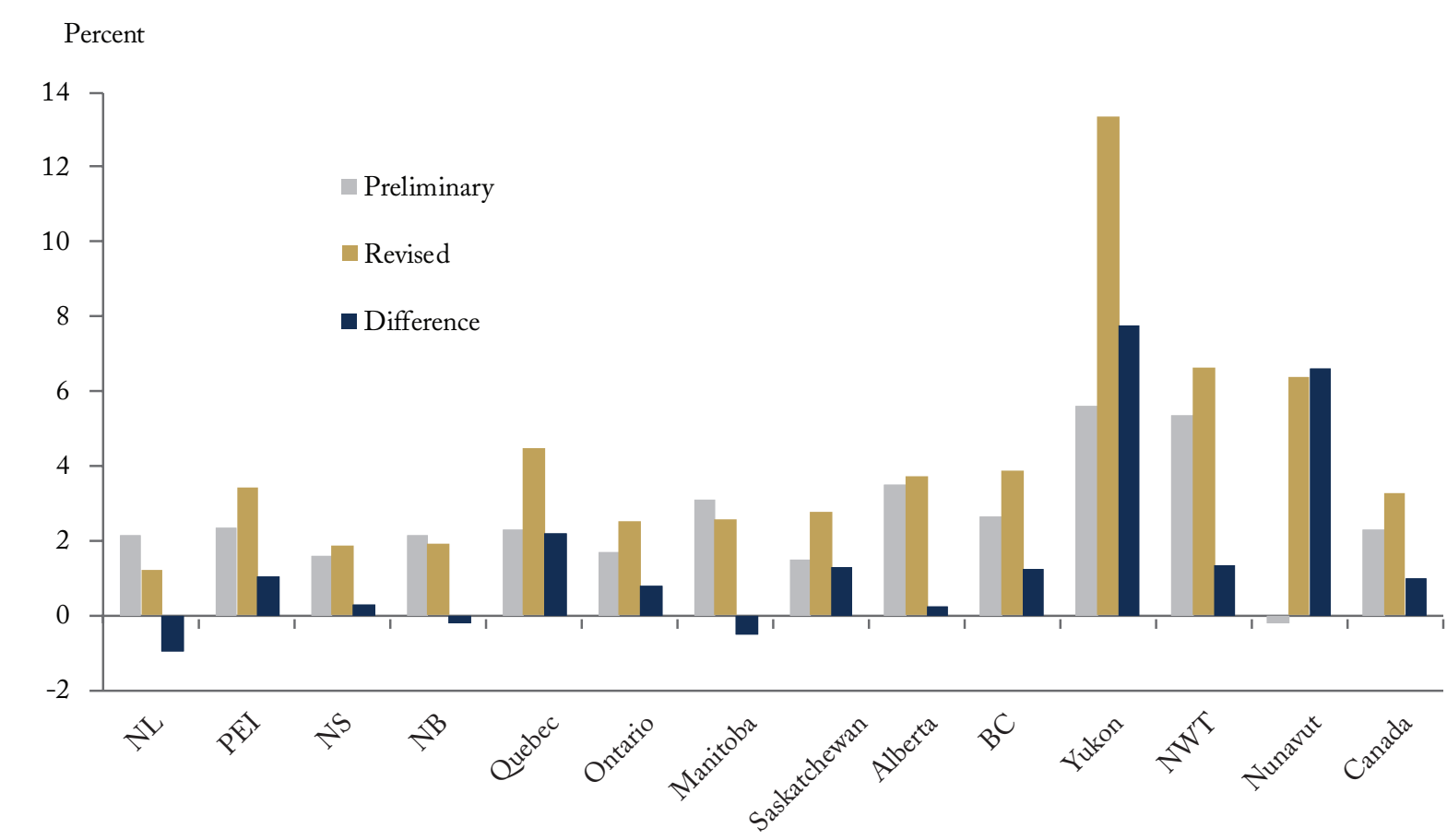

Source: Author's calculations from CIHI NHEX reports.

trend in health-related spending calculated from the revised numbers: over the period for which it and the NHEX reports provide annual numbers, 2008-2017, both sources show an annual growth rate of 4.3 percent. ${ }^{4}$

An 0.8 percent or 1.0 percent overshoot in one jurisdiction in one year is a blip. But overshoots that big across the country, year after year, are a troubling trend. Since 1998, the year of the first NHEX report, they compound to 18.5 percent: almost a one-fifth increase. If governments had actually spent what their preliminary

4 The Statistics Canada compilation - the Canadian Classification of Functions of Government (CCOFOG) - of heathrelated spending captures somewhat more activity than the NHEX report, partly because it consolidates provincial and local government expenses to facilitate comparison across the country. In 2017, the CCOFOG showed $\$ 168.7$ billion in consolidated provincial-territorial and local government health spending, compared to the NHEX report's $\$ 156.7$ billion (Statistics Canada. Table 10-10-0005-01, CCOFOG by consolidated government component). Another important difference is that the CCOFOG includes amortized capital expense rather than the cash outlays of the NHEX reports, which results in a smoother pattern of annual growth figures. Nevertheless, as noted in the text, the annualized growth rates over the 2008-2017 period from the two series are the same. 
numbers indicated, their current healthcare spending would be $\$ 29$ billion lower - more than half of provincial healthcare spending in Ontario - than it is. ${ }^{5}$

Overshoots that large, year after year, can also affect judgments about fiscal sustainability. As is well known, the aging population is pushing governments' health-related spending up. Less widely noted is that the aging of people out of the workforce is slowing growth in GDP and the tax base. Indeed, growth of the working-age population is projected to slow from an annual rate slightly above 1.0 percent over the past three decades to a rate closer to 0.5 percent over the next three (Mahboubi 2019).

Meanwhile, if output per worker were to rise at its historical rate of 1.3 percent, future real GDP growth would be less than 2 percent. But slower workforce growth might reduce the rate of capital accumulation. Based on a constant saving rate out of more slowly growing output, and a consequently lower ratio of capital to workers, annual real GDP growth would be in the 1.5 percent range. ${ }^{6}$ Inflation at the Bank of Canada's 2 percent target rate would produce trend growth in nominal GDP in the 3.5 to 3.8 percent range in the coming decades.

The preliminary 2018 estimate of 3.8 percent spending growth is on the borderline of longer-term sustainability. If later revisions add 0.8 percent to 1.0 percent to it, concerns about the longer-term sustainability of publicly funded health care in Canada become more acute again. ${ }^{7}$

\section{Experience by Jurisdiction}

We can get some insights into the nature of the overshoots from 2014 to 2017 by looking at the provincial and territorial experience during those years. Figure 2 presents 2014-17 averages of preliminary figures (light blue bars), revised figures (gold bars) and the difference between them (dark blue bars) for each jurisdiction. While overshoots are more common than undershoots, they are not universal, and their size varies markedly.

The Atlantic region presents a frugal picture. The preliminary numbers for all four provinces prefigured spending increases of about 2 percent, and the later numbers show minor overshoots and undershoots. Perhaps the chronic fiscal pressure afflicting these provinces has prompted both conservative budgeting and relatively tight expenditure management.

5 The 2018 NHEX report's preliminary numbers put provincial and territorial health spending for that year at $\$ 162.7$ billion. Compounding the annual revisions to calculate a cumulative overshoot is not unreasonable - since the base year for each annual increase includes any previous overshoots. However, calculating the growth rate for each current year from the previous year's figures in the same NHEX report has one potential flaw. The previous year's figures are still partly estimated and they, too, have tended to be slightly lower than in later NHEX reports. By ignoring the upward tendency in the first round of revisions for the sake of a simpler exposition, this analysis slightly understates the tendency for revised growth rates to exceed preliminary ones.

6 These projections are highly speculative: while increasingly scarce and, therefore, costly labour might make capital investment more attractive, historical rates of capital accumulation would drive the ratio of capital to output in the Canadian economy way beyond anything in historical experience - which would presumably lower returns to capital and reduce incentives to save and invest.

7 Revisions to GDP can also affect judgments based on comparisons of growth rates. The most recent analysis of revisions to the national accounts from Statistics Canada (Statistics Canada 2018) showed an average downward revision to growth rates of about 0.1 percent over the 2015-2017 period. 
Figure 3: Changes in Provincial/Territorial Health Spending by Use of Funds, 2014-17, Averages

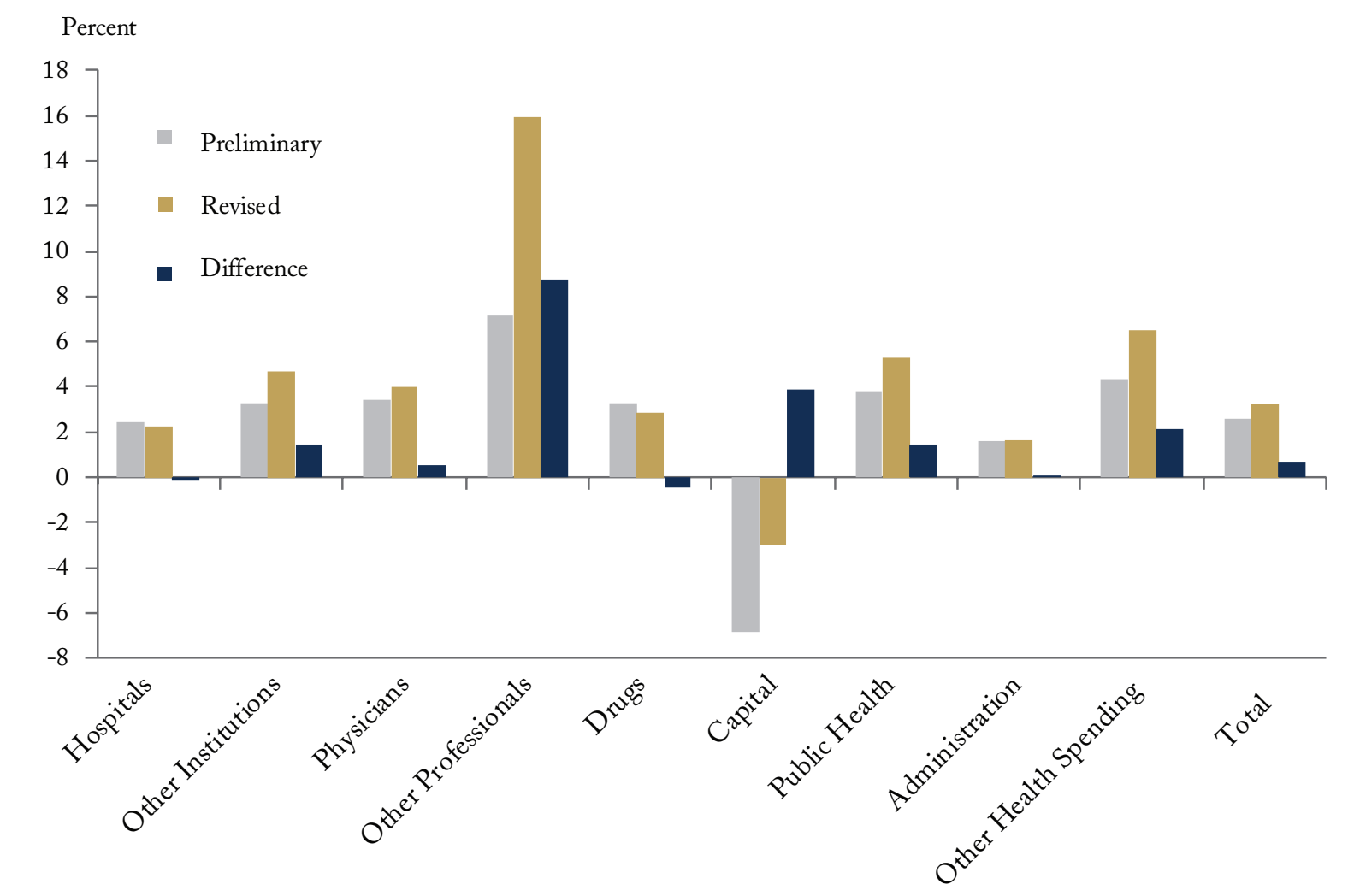

Source: Author's calculations from CIHI NHEX reports.

The preliminary numbers from Quebec suggested modest increases, but the later numbers show a startling overshoot. $^{8}$ Ontario's preliminary numbers suggested even more modest increases, with the later numbers showing a typical NHEX report overshoot of 0.8 percent annually. Notwithstanding reservations about the financial results on the part of the auditors general in those provinces, both have been budgeting on the basis of an improved bottom line and may have felt less obliged to keep spending on a short leash.

Preliminary numbers west of Ontario generally suggested larger increases, which later numbers confirmed and then some, with overshoots everywhere but Manitoba. Better-than-expected resource revenues likely led some of these governments to relax their budget targets and their spending controls.

8 Quebec's overshoot in 2015 - a 0.5 percent increase in the preliminary figures versus a 9.8 percent increase in the revised figures - was large enough to affect the national total. Excluding Quebec, the tally for the rest of the country would have been a 1.8 percent increase in the preliminary figures versus a 3.0 percent increase in the revised figures - an overshoot of 1.2 percent. Unfortunately, the 2016 NHEX report contained no numbers on Quebec's use of funds in 2015 and 2016, so it sheds no light on which categories of spending might account for this huge provincial overshoot. 
Figure 4: Overshoots in Provincial/Territorial Health Spending by Use of Funds, 20142017, Scaled to Preliminary 2018 Spending

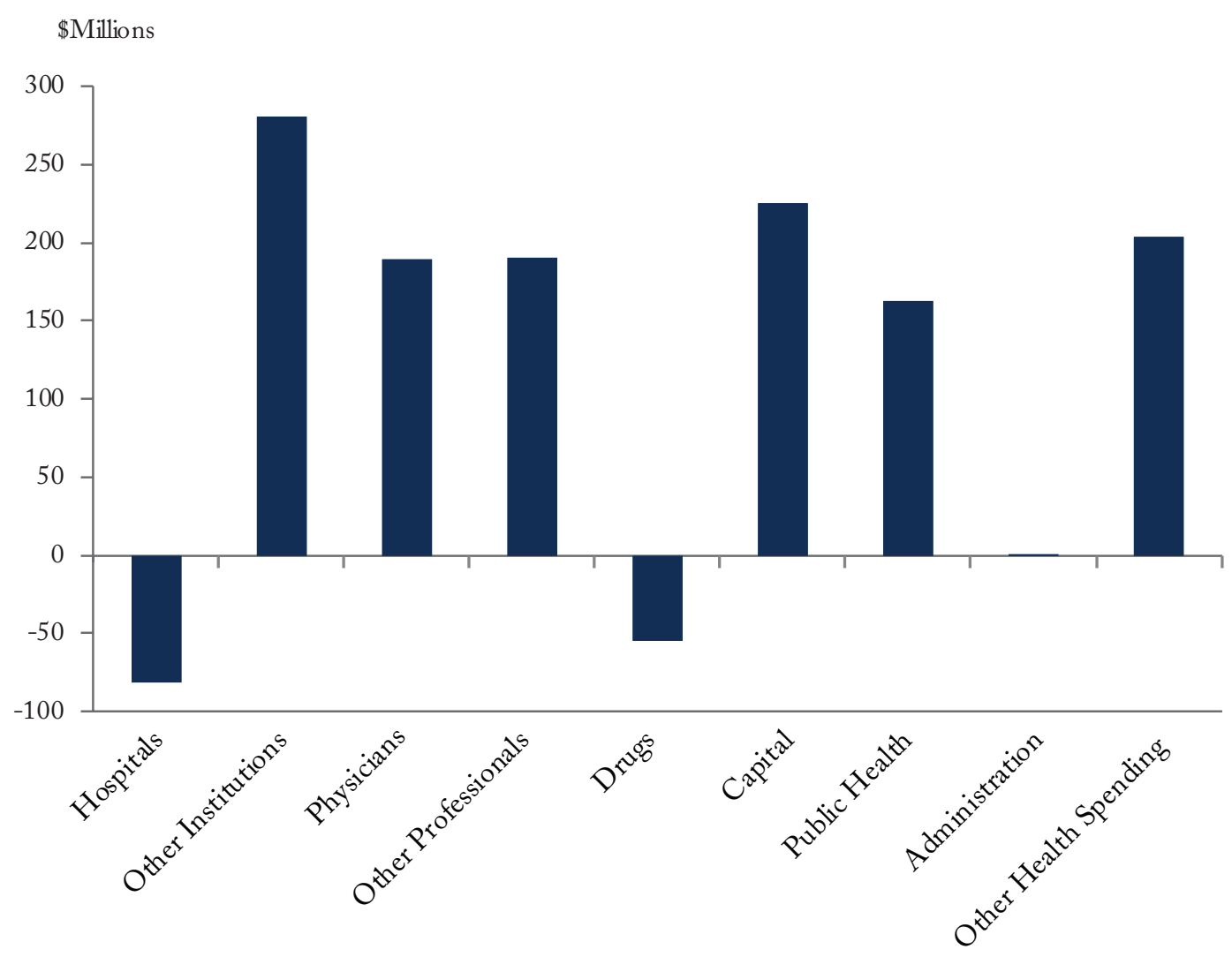

Source: Author's calculations from CIHI NHEX reports.

While Nunavut's preliminary numbers showed a decline, all three territories' later numbers displayed large increases and overshoots. These governments face particular health-service challenges and rapidly rising expectations - and, depending on federal transfers for the bulk of their revenues, may implicitly count on Ottawa to help them out of any healthcare-related budget crises.

\section{Experience by Use of Funds}

A look at various uses of health-related funds provides a second angle on differences between preliminary and later spending numbers. Figure 3 presents 2014-17 averages of preliminary growth rates (light blue bars), revised growth rates (gold bars) and the differences between them (dark blue bars) for the major categories of 
spending that the NHEX reports break out. These are national totals, so they reflect mainly the experience of the larger provinces.?

The preliminary figures indicate that governments generally planned less capital spending and relatively subdued growth for hospital and administration costs. ${ }^{10}$ Governments evidently planned somewhat larger increases for institutions other than hospitals, as well as for doctors, drugs and public health, and much larger increases for other professionals - presumably reflecting desired switches from settings and practices judged to be more costly to those judged to be less costly.

The later numbers show a sometimes surprising mix of hits and misses. On a national basis, actual spending on hospitals undershot marginally, doctors overshot, drugs - an area where rapid growth has been a high-profile issue - undershot, and administration was about on budget. The overshoots on other institutions, public health and the uninformative "other" category were more significant. Other professionals overshot by a huge amount. The other notable overshoot occurred in capital spending, reflecting much smaller declines than planned. ${ }^{11}$

These categories of spending differ greatly in size: hospitals comprise almost 40 percent of provincial/territorial health-related expenses and physicians almost one-quarter, while other professionals and administration are each only about 1 percent. For a better sense of the importance of over- or under-shoots in each, Figure 4 scales the average revisions over the 2014 to 2017 period to projected national spending in $2018 .^{12}$

Spending on hospitals is so large that a marginal undershoot produced a significant dollar saving over these four years. The undershoot on drugs also resulted in a considerable dollar saving. The tendency for unbudgeted increases in compensation for doctors and other healthcare providers to raise expenses is also evident in this view. The term "other" appears in half the categories registering overshoots in the \$150-million-plus range: future NHEX surveys could usefully provide more detail on some of these categories.

Presenting the experience both across the provinces and territories, and by use of funds, together would require a lot of space and detail. For a glance at the jurisdictions and categories of health-related spending that seem most and least prone to overshoots, and their relative importance, Table 1 presents the average differences over the 2014 to 2017 period. Undershoots are white, smaller overshoots are lighter shades of blue and larger

9 Because the 2016 NHEX report contained no numbers on Quebec's use of funds in 2015 and 2016, the national useof-funds numbers here require estimates for Quebec. I interpolate the Quebec numbers, using the proportions in each category from the 2015 and 2017 reports and prorating to match the provincial totals. So, the national numbers are probably not precisely the same as they would have been with more complete Quebec numbers.

10 The NHEX survey tallies cash outlays for capital, rather than the annual amortization expense (as assets deliver their services) that is embodied in current public sector accounting standards and reflected in most provincial budgets and public accounts. So, the capital spending portion of the NHEX report is inconsistent with, and considerably more volatile than, provincial and territorial budgets and public accounts.

11 As noted, the CIHI compilation looks at capital cash outlays. A comparison of expenditures that uses amortization - the consumption of capital already invested - as the measure of spending would show much less year-to-year variation and much smaller differences between intentions and actual results.

12 The estimation of the missing 2016 Quebec numbers likely also affects the national breakdown in this figure. 

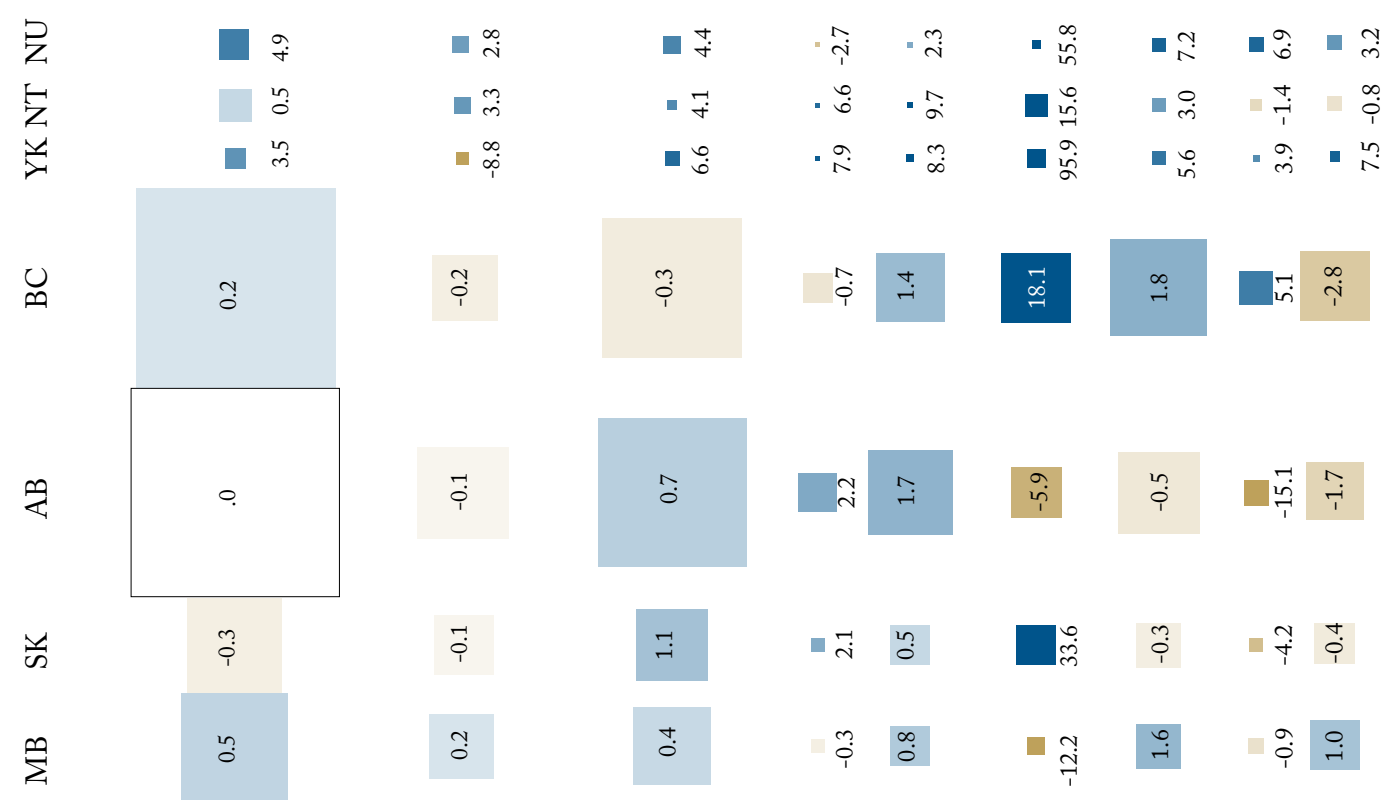

$\Sigma$

v

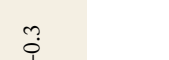

־্ণ

กับ
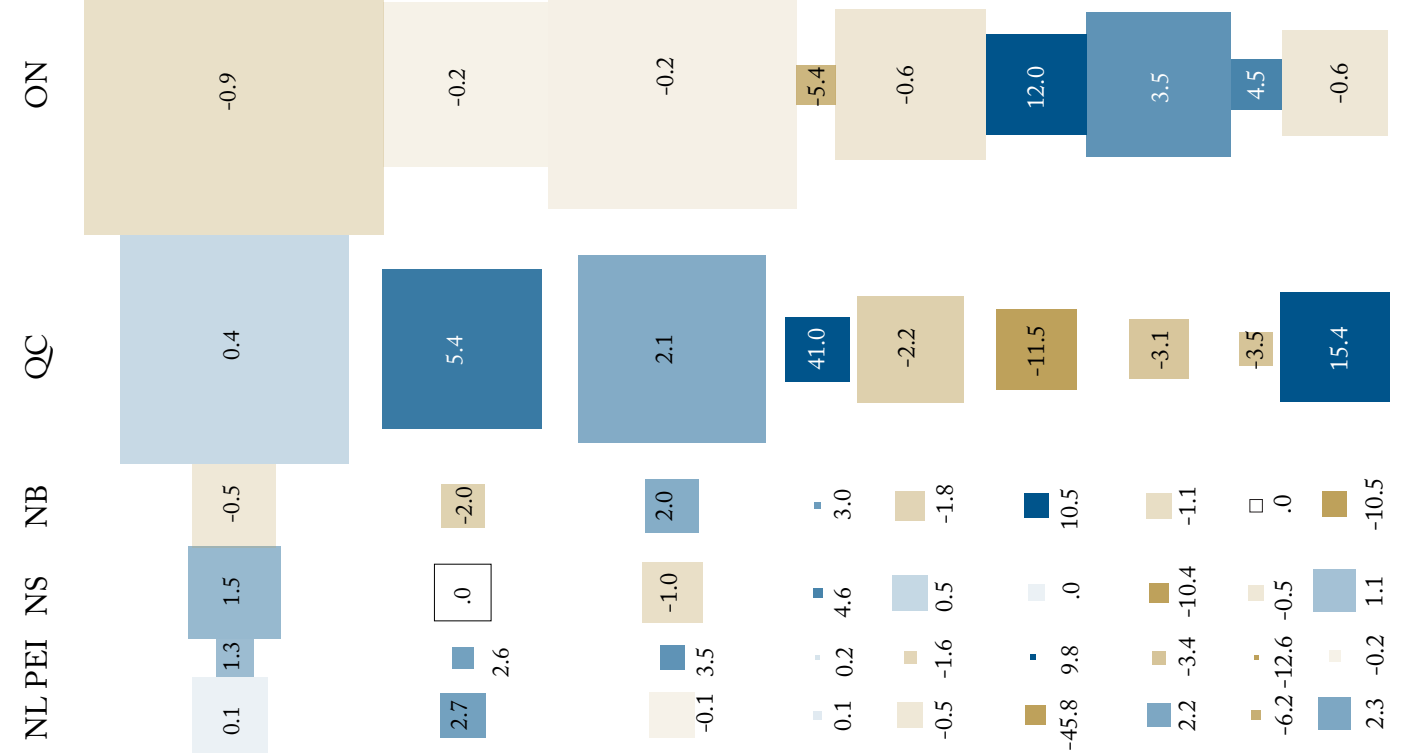

$\stackrel{\circ}{i}$

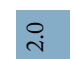

$\circ$.

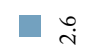

ì

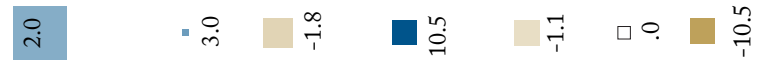

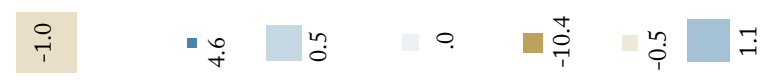

ए

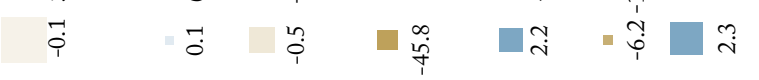

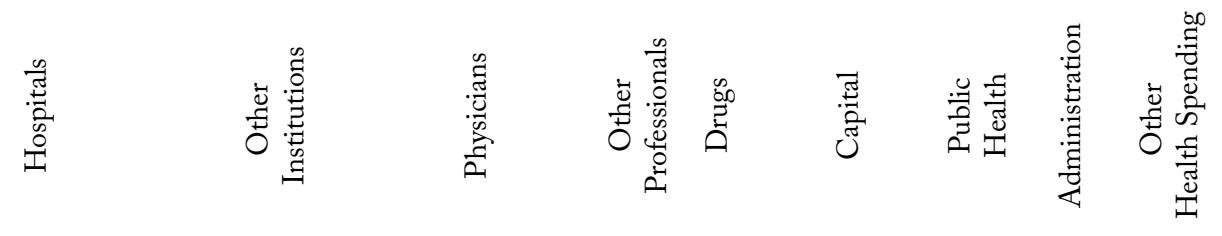


overshoots are darker shades of blue. The widths of the columns for the jurisdictions and the heights of the rows for the categories of spending vary in rough correspondence ${ }^{13}$ to their weight in the national result.

The table highlights that capital spending plans are especially prone to error. "Other professionals" is a pressure point in many jurisdictions. ${ }^{14}$ Drug budgets were relatively well behaved over this period from Ontario east; less so in the West. A striking feature of this presentation is that paler cells exist even in rows with lots of blue - which suggests that provinces and territories that are having problems controlling their budgets in specific areas have opportunities to learn from successful restraint elsewhere.

\section{Keeping Actual Health Spending Sustainable}

This review of the NHEX reports suggests one straightforward kind of change: CIHI should be more cautious about incorporating forward-looking and estimated numbers in its spending figures. Numbers that look more current are naturally more exciting, but evidence that they are systematically misleading should curb enthusiasm for "timely" releases. If the lure of current-looking numbers is too strong to resist, CIHI should avoid emphasizing the estimates at the expense of the actuals and warn users about potential distortions if, for example, differences in finalizing data affect comparisons among different jurisdictions or between publicly and privately funded healthcare expenses.

When it comes to the key questions of how quickly provincial and territorial health-related spending is growing, and whether long-term fiscal sustainability is a concern, the main message of this review is a disappointing one. The preliminary numbers in the NHEX reports have tended to understate actual increases, and the difference between them is material to judgments about fiscal sustainability.

More encouragingly, scans over time, across jurisdictions, and by categories of spending show considerable variation in outcomes. These variations give reason to hope that policy changes might make overshoots of budget plans rarer and smaller in the future.

For one thing, the early years of this decade saw both a sharp decline in planned spending increases and smaller average overshoots across the country, and the same frugality is apparent in the Atlantic provinces in more recent years. Other C.D. Howe Institute research has shown that Canada's provincial and territorial governments typically spent windfalls during the period covered by the NHEX surveys: when revenue came in above budget - as it did more often than not - spending also came in above budget. ${ }^{15}$ Happily, this tendency has been less pronounced in more recent periods (Robson and Omran 2018). Fiscal discipline both in plans and execution can make a difference.

13 To ensure legibility, the graphic makes the smallest jurisdictions and categories larger than true scaling would and, correspondingly, makes the larger jurisdictions and categories somewhat smaller than true scaling would.

14 The interpolation of 2016 numbers for Quebec may exaggerate the extent to which spending on "other professionals" overshot intentions and understate the differences between actual and intended spending in other categories.

15 This is a significant pattern because good macroeconomic management would yield the opposite: when a booming economy brings in better-than-expected revenue, lower demands for income supports and corporate welfare should make spending lower than expected, and vice versa. If revenue and spending "surprises" are in the same direction, governments are spending windfalls and/or managing their bottom lines. 
In delivering healthcare services particularly, governments can align the incentives of providers better with those of the taxpayers who fund the system. They can also align them better with those of the patients who need the care. Although this task is trickier than it would be if market mechanisms, such as consumers paying directly for services, were more common, pursuing high quality and low cost at the same time is not necessarily contradictory. In healthcare, as in many other enterprises, high quality often lowers cost: as when good hospital treatments shorten stays and reduce readmissions.

In recent years, provincial and territorial governments have been budgeting larger increases in health spending - but not so large that, if achieved, they would threaten the long-term sustainability of publicly funded healthcare in Canada. The challenge to sustainability is the unbudgeted increases - the overshoots that show up in the differences between the preliminary numbers in each year's NHEX report and the actual numbers for the same years in later editions of the report. We need better overall fiscal discipline and incentives to keep the cost of publicly funded healthcare in line with our capacity to pay for it. 


\section{References}

Busby, Colin, William Robson, and Aaron Jacobs. 2014. "Managing the Cost of Healthcare for an

Aging Population, 2014: Provincial Perspectives.”Toronto: C.D. Howe Institute. Available online at: https://www.cdhowe.org/public-policy-research/managing-cost-healthcare-aging-population-2014provincial-perspectives. December.

Canadian Institute for Health Information. 2012. “Canada’s health care spending slows.” Ottawa.

. 2013. “Canada curbs health spending as expenditures reach \$211B.” Ottawa. Available online at http://www.marketwired.com/press-release/canada-curbs-health-spending-as-expenditures-reach211b-1846118.htm.

. 2014. “Canada's health spending hits slowest growth rate since 1997.” Ottawa. Available online at http://www.benefitscanada.com/news/health-spending-hits-slowest-growth-rate-since-1997-58748.

- 2015. "Canada's slow health spending growth continues." Ottawa.

2018. “National Health Expenditure Database.” Ottawa.

Mahboubi, Parisa. 2019. Intergenerational Fairness: Will Our Kids Live Better than We Do? Commentary 529. Toronto, C.D. Howe Institute. January.

Mendelsohn, Matthew, and Will Falk. 2013. "How Canada's health care reformers quietly bent the cost curve." Healthydebate: Opinions. November 6. Available online at: http://healthydebate.ca/opinions/ defying-expectations-how-health-care-reformers-quietly-bent-canadas-cost-curve.

Robson, William. 2018. "Healthcare Costs in Canada: Stopping Bad News Getting Worse." E-Brief. Toronto: C.D. Howe Institute. April.

Robson, William, and Farah Omran. 2018. Blown Budgets: Canada's Senior Governments Need Better Fiscal Controls. Commentary 512. Toronto: C.D. Howe Institute. May.

Statistics Canada. 2018. "The 2015 to 2017 Revisions of the Income and Expenditure Accounts." November.

This E-Brief is a publication of the C.D. Howe Institute.

William B.P. Robson is President and CEO of the C.D. Howe Institute.

This E-Brief is available at www.cdhowe.org.

Permission is granted to reprint this text if the content is not altered and proper attribution is provided.

The views expressed here are those of the author. The C.D. Howe Institute does not take corporate positions on policy matters. 